\title{
Free-Water Imaging in White and Gray Matter in Parkinson's Disease
}

\author{
Christina Andica ${ }^{1}\left(\mathbb{D}\right.$, Koji Kamagata $^{1, *}{ }^{-}$, Taku Hatano ${ }^{2}{ }^{(0)}$, Asami Saito ${ }^{1}$, Wataru Uchida ${ }^{1,3}$, \\ Takashi Ogawa ${ }^{2}\left(\mathbb{D}\right.$, Haruka Takeshige-Amano ${ }^{2}$, Andrew Zalesky ${ }^{4,5}$, Akihiko Wada ${ }^{1}(\mathbb{D}$, \\ Michimasa Suzuki ${ }^{1}$, Akifumi Hagiwara ${ }^{1}\left(\mathbb{D}\right.$, Ryusuke Irie ${ }^{1,6}{ }^{\circ}$, Masaaki Hori ${ }^{1,7}(\mathbb{D}$, \\ Kanako K. Kumamaru ${ }^{1}$, Genko Oyama ${ }^{2}$, Yashushi Shimo ${ }^{2}$, Atsushi Umemura ${ }^{8}$, \\ Christos Pantelis ${ }^{4,5,9}$, Nobutaka Hattori ${ }^{2}$ (D) and Shigeki Aoki ${ }^{1}$ \\ 1 Department of Radiology, Juntendo University Graduate School of Medicine, Tokyo 113-8421, Japan \\ 2 Department of Neurology, Juntendo University School of Medicine, Tokyo 113-8421, Japan \\ 3 Department of Radiological Sciences, Tokyo Metropolitan University, Graduate School of Human Health \\ Sciences, Tokyo 116-8551, Japan \\ 4 Melbourne Neuropsychiatry Centre, Department of Psychiatry, The University of Melbourne \& Melbourne \\ Health, Parkville, VIC 3053, Australia \\ 5 Melbourne School of Engineering, The University of Melbourne, VIC 3010, Australia \\ 6 Department of Radiology, The University of Tokyo Graduate School of Medicine, Tokyo 113-0033, Japan \\ 7 Department of Radiology, Toho University Omori Medical Center, Tokyo 143-8541, Japan \\ 8 Department of Neurosurgery, Juntendo University School of Medicine, Tokyo 113-8421, Japan \\ 9 Florey Institute for Neuroscience and Mental Health, Parkville, VIC 3052, Australia \\ * Correspondence: kkamagat@juntendo.ac.jp; Tel.: +81-358-021-230
}

Received: 28 June 2019; Accepted: 3 August 2019; Published: 5 August 2019

check for updates

\begin{abstract}
This study aimed to discriminate between neuroinflammation and neuronal degeneration in the white matter (WM) and gray matter (GM) of patients with Parkinson's disease (PD) using free-water (FW) imaging. Analysis using tract-based spatial statistics (TBSS) of 20 patients with PD and 20 healthy individuals revealed changes in FW imaging indices (i.e., reduced FW-corrected fractional anisotropy $\left(\mathrm{FA}_{\mathrm{T}}\right)$, increased $\mathrm{FW}$-corrected mean, axial, and radial diffusivities $\left(\mathrm{MD}_{\mathrm{T}}, \mathrm{AD}_{\mathrm{T}}\right.$, and $\mathrm{RD}_{\mathrm{T}}$, respectively) and fractional volume of FW (FW) in somewhat more specific WM areas compared with the changes of DTI indices. The region-of-interest (ROI) analysis further supported these findings, whereby those with PD showed significantly lower $\mathrm{FA}_{\mathrm{T}}$ and higher $\mathrm{MD}_{\mathrm{T}}, \mathrm{AD}_{\mathrm{T}}$, and $\mathrm{RD}_{\mathrm{T}}$ (indices of neuronal degeneration) in anterior WM areas as well as higher FW (index of neuroinflammation) in posterior WM areas compared with the controls. Results of GM-based spatial statistics (GBSS) analysis revealed that patients with PD had significantly higher $\mathrm{MD}_{\mathrm{T}}, \mathrm{AD}_{\mathrm{T}}$, and $\mathrm{FW}$ than the controls, whereas $\mathrm{ROI}$ analysis showed significantly increased $\mathrm{MD}_{\mathrm{T}}$ and $\mathrm{FW}$ and a trend toward increased $\mathrm{AD}_{\mathrm{T}}$ in $\mathrm{GM}$ areas, corresponding to Braak stage IV. These findings support the hypothesis that neuroinflammation precedes neuronal degeneration in PD, whereas WM microstructural alterations precede changes in GM.
\end{abstract}

Keywords: Parkinson's disease; neuronal degeneration; neuroinflammation; diffusion tensor imaging; free-water imaging; tract-based spatial statistics; gray matter-based spatial statistics

\section{Introduction}

Parkinson's disease (PD) is characterized by widespread aggregation of $\alpha$-synucleinimmunoreactive inclusions in the form of Lewy pathology [1]. Lewy pathology was recently demonstrated to trigger reactive microgliosis before nigral degeneration in animal models of PD [2]. Distinguishing between neuroinflammation and neuronal degeneration in vivo may provide a better understanding of the progression of PD pathology. 
Diffusion tensor imaging (DTI) has been widely used in the evaluation of brains of patients with PD [3]. DTI indices such as fractional anisotropy (FA), mean diffusivity (MD), axial diffusivity (AD), and radial diffusivity $(\mathrm{RD})$ characterize the orientation and distribution of the random movements of water molecules, diffusion magnitude, diffusional directionality perpendicular to the axon, and diffusional directionality along the axon, respectively [4]. Despite their sensitivity, DTI indices are not tissue specific [5]. Furthermore, the assumption of a single-tissue compartment per voxel such that partial volume effect averaging in a voxel from free water (FW) [4] can introduce a bias in the interpretation of DTI indices [6]. In the human brain, FW is present as cerebrospinal fluid (CSF); however, it may also accumulate within the extracellular spaces of the brain parenchyma owing to brain pathologies, such as neuroinflammation, tumor, and trauma $[7,8]$. Studies involving the use of DTI in patients with PD reported reduced FA [9,10] and increased MD [11,12]. A decrease in FA accompanied by increased MD may be attributed to neuronal degeneration and/or neuroinflammation [13]. Thus, the use of these indices might not be useful in differentiating between these pathologies.

Conversely, FW imaging was developed to quantify the contribution of FW and eliminate bias when estimating tissue microstructures and enabled differentiation between alterations in the tissues themselves, such as neuronal degeneration, as measured by FW-corrected DTI indices $\left(\mathrm{FA}_{\mathrm{T}}, \mathrm{MD}_{\mathrm{T}}, \mathrm{AD}_{\mathrm{T}}\right.$, and $\mathrm{RD}_{\mathrm{T}}$, respectively), and extracellular FW changes, such as neuroinflammation, as measured by the fractional volume of FW [7]. FW imaging is achieved by adopting a two-compartment model and fitting 2 tensors into the diffusion data [7]. In PD, FW imaging has thus far only been used to evaluate the substantia nigra. FW within the substantia nigra is considered to be a promising biomarker for distinguishing patients with PD from healthy individuals and as a biomarker for disease progression [14,15].

We hypothesize that applying FW correction to DTI data will improve the detection of abnormalities associated with PD in DTI indices. Specifically, the use of FW imaging might allow the discrimination between neuroinflammation and neuronal degeneration in white matter (WM) and gray matter (GM) in PD. To test this hypothesis, we compared 20 patients with PD to 20 control individuals using DTI and FW imaging.

\section{Materials and Methods}

\subsection{Subjects}

Twenty patients with PD in Hoehn and Yahr stage 1-2 and 20 age- and sex-matched controls with no history of neurologic or psychiatric disorders and no abnormal signals on structural magnetic resonance imaging (MRI) were included in this retrospective case-control study. Patients with PD were diagnosed by specialists based on the clinical diagnostic criteria for PD by the Movement Disorder Society [16]. Disease severity was assessed using non-motor and motor scores of the Movement Disorder Society's Unified Idiopathic PD Rating Scale (UPDRS) parts I and III, respectively. All patients with PD remained free from atypical parkinsonism and exhibited good response $(>30 \%$ in UPDRS part III score with change in treatment or a clearly documented history of marked changes from a reliable patient or caregiver [16]) to anti-parkinsonian therapy for 18 months or more after the initial diagnosis. At the time of MRI and clinical examinations, all patients were taking levodopa in combination with a dopamine decarboxylase inhibitor (benserazide or carbidopa). All patients with PD underwent single-photon computed tomography imaging of dopamine transporters and demonstrated deficits in specific binding ratio (less than $95 \%$ of the lower limit of prediction intervals for healthy Japanese population) [17]. The clinical phenotypes of PD, including tremor-dominant $(n=6)$, postural instability/gait difficulty $(n=8)$, and intermediate $(n=6)$, were assessed using UPDRS part III in all patients with PD [18]. Furthermore, in all patients with PD, rapid eye movement sleep behavior disorder (RBD) $(n=8)$ was assessed using the RBD single-question screen (RBD1Q) [19]. Table 1 summarizes the demographic and clinical characteristics of healthy controls and patients with PD. The ethics committee approved this study, and all participants signed a written informed consent. 
Table 1. Demographic characteristics of the study participants.

\begin{tabular}{|c|c|c|c|c|c|c|c|c|}
\hline & $\mathrm{HC}$ & All PD & $\begin{array}{l}\text { Right-Sided } \\
\text { Onset PD }\end{array}$ & $\begin{array}{l}\text { Left-Sided } \\
\text { Onset PD }\end{array}$ & $\begin{array}{c}P \text { Value (HC } \\
\text { vs. All PD }\end{array}$ & $\begin{array}{l}P \text { Value (R vs. } \\
\text { L Onset PD) }\end{array}$ & $\begin{array}{c}P \text { Value (HC vs. } \\
\text { R Onset PD) }\end{array}$ & $\begin{array}{c}P \text { Value (HC vs } \\
\text { L Onset PD) }\end{array}$ \\
\hline Number & 20 & 20 & 12 & 8 & - & - & - & - \\
\hline Sex, $N$ (male/female) ${ }^{\circ}$ & $12 / 8$ & $11 / 9$ & $5 / 7$ & $6 / 2$ & 0.75 & 0.14 & 0.31 & 0.45 \\
\hline Age $($ mean years $\pm S D) *$ & $67.15 \pm 1.18$ & $65.05 \pm 10.9$ & $63.50 \pm 11.13$ & $67.38 \pm 8.43$ & 0.52 & 0.16 & 0.15 & 0.91 \\
\hline Disease duration (mean years $\pm S D$ ) & - & $6.95 \pm 3.93$ & $7.5 \pm 3.63$ & $6.13 \pm 4.45$ & - & 0.46 & - & - \\
\hline MDS-UPDRS part I $($ mean \pm SD) * & - & $5.45 \pm 2.93$ & $5.25 \pm 2.45$ & $5.75 \pm 3.69$ & - & 0.72 & - & - \\
\hline \multicolumn{9}{|l|}{ MDS-UPDRS part I subscores (mean \pm SD) * } \\
\hline Cognitive (I.1) & - & $0.15 \pm 0.37$ & $0.17 \pm 0.39$ & $0.13 \pm 0.35$ & - & 0.81 & - & - \\
\hline Neuropsychiatric (I.2-I.6) & - & $1.20 \pm 1.32$ & $1.00 \pm 1.04$ & $1.50 \pm 1.69$ & - & 0.42 & - & - \\
\hline Sleep disorder (I.7, I.8) & - & $1.45 \pm 1.28$ & $1.25 \pm 1.22$ & $1.75 \pm 1.39$ & - & 0.41 & - & - \\
\hline Sensory and others (I.9, I.13) & - & $0.90 \pm 1.02$ & $1.83 \pm 1.11$ & $1.63 \pm 0.74$ & - & 0.61 & - & - \\
\hline Autonomic (I.10-I.12) & - & $1.75 \pm 0.97$ & $1.83 \pm 1.11$ & $1.63 \pm 0.74$ & - & 0.65 & - & - \\
\hline MDS-UPDRS part III (mean \pm SD) * & - & $11.05 \pm 5.22$ & $11.25 \pm 4.86$ & $10.75 \pm 6.04$ & - & 0.84 & - & - \\
\hline Hoehn and Yahr staging (mean $\pm \mathrm{SD}) *$ & - & $1.85 \pm 0.37$ & 1.750 .45 & $2 \pm 0$ & & 0.14 & - & - \\
\hline $1, N(\%)$ & - & $3(15 \%)$ & $3(25 \%)$ & $0(0 \%)$ & - & - & - & - \\
\hline $2, N(\%)$ & - & $17(85 \%)$ & $9(75 \%)$ & $8(100 \%)$ & - & - & - & - \\
\hline $\operatorname{LED}($ mean $\pm \mathrm{SD})$ * & - & $862.25 \pm 596.50$ & $898.75 \pm 607.84$ & $807.50 \pm 616.02$ & - & 0.75 & - & - \\
\hline Mean SBR $($ mean \pm SD) & - & $3.28 \pm 1.27$ & - & - & - & - & - & \\
\hline
\end{tabular}

HC, healthy controls; LED, levodopa equivalent dose; L, left; MDS-UPDRS, Movement Disorder Society's Unified Parkinson's Disease Rating Scale; PD, Parkinson's disease; R, right; SBR, specific binding ratio; SD, standard deviation. Note. Statistical analyses were performed using the $\chi^{2}$ test $\left(^{\circ}\right)$ or unpaired Student's $t$-test $\left({ }^{*}\right)$. MDS-UPDRS part I subscores: $(1)$ cognitive impairment, (2) hallucinations, (3) depression, (4) anxiety, (5) apathy, (6) dopamine dysregulation syndrome, (7) sleep problems, (8) daytime sleepiness, (9) pain, (10) urinary problem, (11) constipation, (12) light headedness on standing, (13) fatigue. 


\subsection{Acquisition of MRI Data}

All MRI data were acquired using a 3-T scanner (MAGNETOM Prisma; Siemens Healthcare, Erlangen, Germany) with a 64-channel head coil. Whole-brain diffusion-weighted imaging and 3D magnetization-prepared $180^{\circ}$ radio-frequency pulses and rapid gradient-echo (MP-RAGE) T1-weighted imaging were obtained for all subjects. Whole-brain diffusion-weighted images were acquired using spin-echo planar imaging with the following parameters: repetition time, $3300 \mathrm{~ms}$; echo time, $70 \mathrm{~ms}$; flip angle, $90^{\circ}$; diffusion gradient directions, 64 ; $b$-values, 0 and $1000 \mathrm{~s} / \mathrm{mm}^{2}$; field of view, $229 \times 229 \mathrm{~mm}$; matrix size, $130 \times 130$; resolution, $1.8 \times 1.8 \mathrm{~mm}$; slice thickness, $1.6 \mathrm{~mm}$; and acquisition time, $3 \mathrm{~min} 55 \mathrm{~s}$. 3D MP-RAGE T1-weighted images were acquired using the following parameters: repetition time, $2300 \mathrm{~ms}$; echo time, $2.32 \mathrm{~ms}$; inversion time, $900 \mathrm{~ms}$; field of view, $240 \times 240 \mathrm{~mm}$; matrix size, $256 \times 256$; resolution, $0.9 \times 0.9 \mathrm{~mm}$; slice thickness, $0.9 \mathrm{~mm}$; and acquisition time, $6 \mathrm{~min} 25 \mathrm{~s}$.

\subsection{Diffusion MRI Preprocessing}

All diffusion MRI data from 64 different axial, sagittal, and coronal directions were visually checked. Moreover, all datasets were free from severe artifacts such as gross geometric distortion, signal dropout, or bulk motion. Diffusion MRI data were then corrected for susceptibility-induced geometric distortions, eddy current distortions, and inter-volume subject motion using EDDY and TOPUP toolboxes [20].

Single-tensor FA, MD, AD, and RD maps were generated using the DTIFIT tool implemented in FMRIB Software Library version 5.0.9 (FSL; Oxford Centre for Functional MRI of the Brain, Oxford, UK; www.fmrib.ox.ac.uk/fsl). Meanwhile, an in-house MATLAB (MathWorks, Natick, MA, USA) script was used to fit a regularized bi-tensor model and generate maps for $\mathrm{FA}_{\mathrm{T}}, \mathrm{MD}_{\mathrm{T}}, \mathrm{AD}_{\mathrm{T}}, \mathrm{RD}_{\mathrm{T}}$, and $\mathrm{FW}$. A more detailed description of the methods is discussed elsewhere [7].

\subsection{Voxel-Wise Analysis}

Tract-based spatial statistics (TBSS) [21] and GM-based spatial statistics (GBSS) [22] implemented in the FSL [23] were used to regionally map significant differences between groups in all DTI (FA, MD, $\mathrm{AD}$, and $\mathrm{RD})$ and $\mathrm{FW}$ imaging $\left(\mathrm{FA}_{\mathrm{T}}, \mathrm{MD}_{\mathrm{T}}, \mathrm{AD}_{\mathrm{T}}, \mathrm{RD}_{\mathrm{T}}\right.$, and $\left.\mathrm{FW}\right)$ indices for $\mathrm{WM}$ and $\mathrm{GM}$, respectively, as well as to evaluate the relationship of each index with disease duration and clinical scores such as the scores of UPDRS parts I and III.

\subsubsection{TBSS}

WM was analyzed using the skeleton projection step of TBSS [21] using the following steps. First, FA maps of all subjects were aligned to the standard Montreal Neurological Institute (MNI) space (MNI152) with the FMRIB non-linear registration tool [24]. Next, a mean FA image was generated and thinned to create the mean FA skeleton, which represented the centers of all tracts common to the groups. Next, the threshold of the mean FA skeleton was set to FA $>0.20$ to include major WM pathways and exclude peripheral tracts and GM. Finally, the aligned FA map of each subject was projected onto the FA skeleton. The same process was applied to other single-tensor DTI (MD, AD, and $\mathrm{RD}$ ) and bi-tensor $\mathrm{FW}$ imaging $\left(\mathrm{FW}, \mathrm{FA}_{\mathrm{T}}, \mathrm{MD}_{\mathrm{T}}, \mathrm{AD}_{\mathrm{T}}\right.$, and $\left.\mathrm{RD}_{\mathrm{T}}\right)$ maps such that the maps were projected onto the mean $\mathrm{FA}$ without the initial registration.

\subsubsection{GBSS}

GM was analyzed using GBSS [22], a GM analog of TBSS, using the following steps. First, the Brain Extraction Tool was used to remove non-brain voxels from each subject's 3D T1-weighted images. Next, each skull-stripped 3D T1-weighted image was affine- and non-linearly aligned to an MNI152 standard space at a 1-mm resolution using the FMRIB linear image registration tool and the FMRIB non-linear registration tool [24], respectively. Next, field bias was corrected, and GM, WM, and CSF segmentations were obtained using the FMRIB automated segmentation tool [25]. The resulting 
GM image was then used to create a median GM skeleton with a threshold of 0.2 to minimize the contribution of voxels from WM and CSF. Next, $b 0$ maps of each subject were affine-aligned to their 3D T1-weighted images (epi-reg). After all maps were affine- and non-linearly aligned into an MNI152 brain common space at a 1-mm resolution [24], the aligned maps of each subject were projected onto the median GM skeleton map.

\subsection{Region-of-Interest Analysis}

WM and GM were further evaluated using automatic region-of-interest (ROI) analyses. Maps showing significant clusters on TBSS and GBSS analyses were localized using Johns Hopkins University's ICBM-DTI-81 WM labels and tractography atlases and the Desikan-Killiany atlas, respectively. The average diffusion metric was averaged over all WM and GM skeleton voxels comprising a given region delineated by the atlases for all subjects.

Based on the TBSS results, WM was divided into an anterior portion, comprising forceps minor, bilateral anterior corona radiata, and anterior thalamic radiation, and a posterior portion comprising forceps major, bilateral posterior corona radiata, and posterior thalamic radiation.

PD progresses according to the distribution pattern of Lewy pathology deposition defined by Braak staging, whereas motor symptoms appear when the Lewy pathology reaches stage III [26]. Given that all patients with PD included in the present study showed motor symptoms at the time of examination, GM was analyzed based on Braak staging, which comprised hippocampus, para-hippocampal gyrus, amygdala, cingulate cortices, and thalamus for stage IV; temporal, frontal and parietal association cortices and striatum for stage V; and primary sensory or motor cortices for stage VI [27,28].

\subsection{Voxel-Based Morphometry}

Voxel-based morphometry was used to obtain WM and GM volumetry. First, 3D T1-weighted images were segmented into GM, WM, and CSF through a unified tissue segmentation model using the Statistical Parametric Mapping 12 software (Wellcome Department of Imaging Neuroscience, London, UK; http://www.fil.ion.ucl.ac.uk/spm/software/spm12/) running on a MATLAB 2014a platform (MathWorks; https://www.mathworks.com/products/matlab.html) [29]. Segmented GM and WM images were then spatially normalized to the customized template in the standardized anatomic space using the Diffeomorphic Anatomical Registration Through Exponentiated Lie Algebra (DARTEL) algorithm [30]. To preserve GM and WM volumes within each voxel, Jacobean determinants derived from spatial normalization using DARTEL and an $8 \mathrm{~mm}$ full-width at half maximum Gaussian kernel were used to modulate and smooth the images, respectively.

\subsection{Statistical Analysis}

All statistical analyses were performed using IBM SPSS Statistics for Windows, version 22.0 (IBM Corporation, Armonk, NY, USA), except for general linear model analysis, where the FSL [23] was used. The Shapiro-Wilk test was used to assess data normality, whereas demographic data were analyzed using unpaired Student's $t$-test and the $\chi^{2}$ test for continuous and categorical variables, respectively. Statistical significance for all two-tailed tests was set at 0.05 .

For TBSS and GBSS analyses, a general linear model framework including unpaired Student's t-test (healthy controls vs. all patients with PD) and one-way analysis of variance (healthy controls vs. patients with right-sided PD vs. those with left-sided PD), with age and sex as covariates, and the randomize tool was used with 5000 permutations to compare all diffusion indices between groups. Results were then corrected for multiple comparisons by controlling for family wise error (FWE) and applying threshold-free cluster enhancement. An FWE-corrected $P$ value of 0.05 was considered to indicate statistical significance. The randomize tool was also applied during voxel-wise correlation analysis of each index with disease duration, UPDRS part I score, UPRDRS part I subscores (cognitive, neuropsychiatric, sleep disorder, sensory and others, and autonomic), or UPDRS part III score. 
Unpaired Student's $t$-test was used to assess differences between the healthy control and PD groups according to the ROI of each metric that showed significant group differences in the TBSS analysis of WM and GM. Bonferroni's correction was used for multiple comparisons in WM $(n=2$, anterior and posterior) and GM $(n=3$, stages IV, V, and VI) with the level of significance for two-tailed $P$ values set at $0.025(0.05 / 2)$ and $0.017(0.05 / 3)$, respectively. The effect size was then calculated using Cohen's $d$ [31] to evaluate the statistical power of the relationship determined during group comparisons. Average diffusion metrics of the WM and GM ROIs were then correlated with disease duration or UPDRS part I score, UPDRS part I subscores (cognitive, neuropsychiatric, sleep disorder, sensory and others, and autonomic), or UPDRS part III score. Considering the exploratory nature of this analysis, Bonferroni correction was not applied.

The volumes were compared between the patients with PD and healthy controls using a generalized linear model for analysis of covariance, with age, sex, and total intracranial volume as covariates using the FWE rate set at $p=0.05$.

\section{Results}

\subsection{WM Alterations}

\subsubsection{TBSS}

Figure 1 and Table 2 show the results of the TBSS analysis for DTI (FA, MD, AD, and RD) and FW $\left(\mathrm{FA}_{\mathrm{T}}, \mathrm{MD}_{\mathrm{T}}, \mathrm{AD}_{\mathrm{T}}, \mathrm{RD}_{\mathrm{T}}\right.$, and $\left.\mathrm{FW}\right)$ imaging indices. The patients with $\mathrm{PD}$ exhibited significantly lower $\mathrm{FA}$ and $\mathrm{FA}_{\mathrm{T}}$ and higher $\mathrm{MD}, \mathrm{MD}_{\mathrm{T}}, \mathrm{AD}, \mathrm{AD}_{\mathrm{T}}, \mathrm{RD}, \mathrm{RD}_{\mathrm{T}}$, and $\mathrm{FW}(p<0.05, \mathrm{FWE}$-corrected) compared with the healthy controls. While changes in the DTI indices were observed across broad areas, changes in the FW imaging indices were observed in relatively limited areas. Furthermore, the reduced $\mathrm{FA}_{\mathrm{T}}$ and the increased $\mathrm{MD}_{\mathrm{T}}$ and $\mathrm{AD}_{\mathrm{T}}$ were predominantly observed in the anterior portion, whereas the increased FW was observed in the posterior WM. The details on the anatomical region, peak $t$-value, and peak MNI coordinates of significant clusters are presented in Table 2. There were no significant differences in the DTI and FW imaging indices between the patients with right-sided and left-sided onset PD, the healthy controls and the patients with right-sided onset PD, or the healthy controls and the patients with left-sided onset PD.

\subsubsection{ROI}

Figure 2 and Table 3 show the ROI analysis results for DTI (FA, MD, AD, and RD) and FW imaging $\left(\mathrm{FA}_{\mathrm{T}}, \mathrm{MD}_{\mathrm{T}}, \mathrm{AD}_{\mathrm{T}}, \mathrm{RD}_{\mathrm{T}}\right.$, and $\left.\mathrm{FW}\right)$ indices in the anterior and posterior $\mathrm{WM}$ tracts. Within the anterior WM tracts, the patients with PD exhibited significantly lower FA and $F A_{T}$ and higher MD, RD, $\mathrm{MD}_{T}$, $\mathrm{AD}_{\mathrm{T}}$, and $\mathrm{RD}_{\mathrm{T}}$ compared with the healthy controls. Moreover, the patients with $\mathrm{PD}$ tended to have higher AD compared with the healthy controls. Within the posterior WM tracts, the patients with PD exhibited significantly lower FA and higher RD and FW compared with the healthy controls. Moreover, the patients with PD tended to have higher MD compared with the healthy controls. 


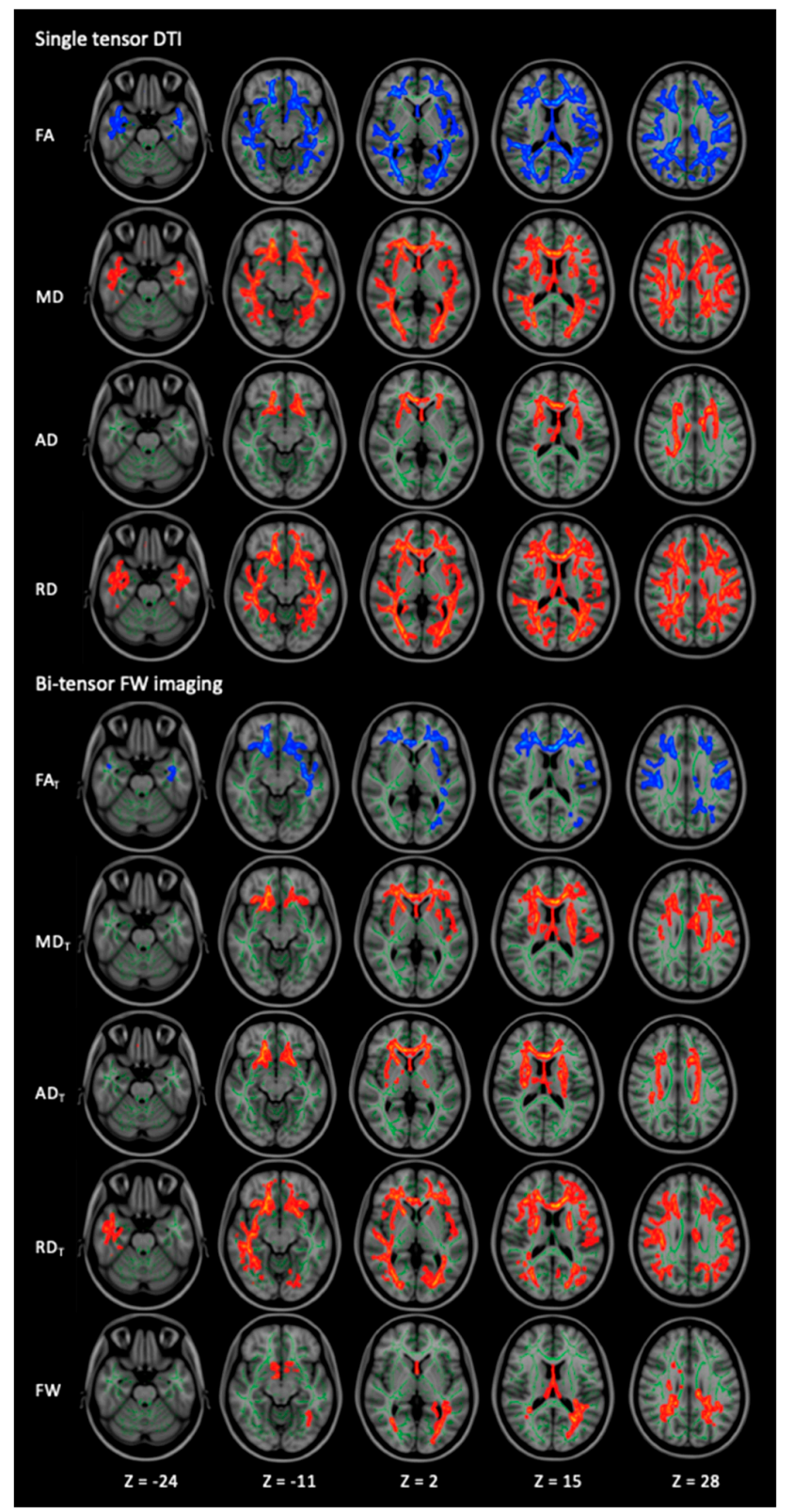

Figure 1. Comparison of DTI (FA, MD, $\mathrm{AD}$, and $\mathrm{RD}$ ) and $\mathrm{FW}$ imaging $\left(\mathrm{FA}_{\mathrm{T}}, \mathrm{MD}_{\mathrm{T}}, \mathrm{AD}_{\mathrm{T}}, \mathrm{RD}_{\mathrm{T}}\right.$, and $\left.\mathrm{FW}\right)$ indices between healthy controls and patients with PD. TBSS analyses show that patients with PD have significantly ( $p<0.05$, FWE-corrected) lower FA and FA $\mathrm{T}_{\mathrm{T}}$ (blue/light-blue voxels) and significantly higher $\mathrm{MD}, \mathrm{MD}_{\mathrm{T}}, \mathrm{AD}, \mathrm{AD}_{\mathrm{T}}, \mathrm{RD}, \mathrm{RD}_{\mathrm{T}}$, and $\mathrm{FW}$ (red-yellow voxels) compared with healthy controls. The skeleton is presented in green. To aid visualization, the results are thickened using the fill script implemented in the FMRIB Software Library. $\mathrm{AD}$, axial diffusivity; $\mathrm{AD}_{\mathrm{T}}$, free water-corrected axial diffusivity; DTI: diffusion tensor imaging; $\mathrm{FA}$, fractional anisotropy; $\mathrm{FA}_{\mathrm{T}}$, free water-corrected fractional anisotropy; FW, free water; $\mathrm{MD}$, mean diffusivity; $\mathrm{MD}_{\mathrm{T}}$, free water-corrected mean diffusivity; $\mathrm{PD}$, Parkinson's disease; $\mathrm{RD}$, radial diffusivity; $\mathrm{RD}_{\mathrm{T}}$, free water-corrected radial diffusivity; TBSS, tract-based spatial statistics. 
Table 2. Tract-based spatial statistics analysis of diffusion tensor and free-water imaging indices in patients with Parkinson's disease and healthy controls.

\begin{tabular}{|c|c|c|c|c|c|}
\hline Modality & Contrast & Cluster Size & Anatomical Region & Peak $t$-Value & $\begin{array}{c}\text { Peak MNI Coordinates } \\
(X, Y, Z)\end{array}$ \\
\hline FA & $\mathrm{HC}>\mathrm{PD}$ & 46483 & $\begin{array}{c}\text { Single-tensor DTI } \\
\text { Bilateral ATR, CST, CgH, IFOF, ILF, SLF, UF, temporal part of the SLF, } \\
\text { retrolenticular part of the IC, ACR, SCR, PCR, PTR, sagittal stratum, external } \\
\text { capsule, tapatum; Lt-CCG; Rt-PLIC; fornix, forceps major and minor, genu, } \\
\text { body and splenium of CC }\end{array}$ & 6.81 & $133,124,44$ \\
\hline MD & $\mathrm{HC}<\mathrm{PD}$ & 39448 & $\begin{array}{l}\text { Bilateral ATR, CST, IFOF, ILF, SLF, UF, temporal part of the SLF, ALIC, PLIC, } \\
\text { retrolenticular part of the IC, ACR, SCR, PCR, PTR, sagittal stratum, external } \\
\text { capsule, SFOF, tapatum; genu, body and splenium of CC, fornix and forceps } \\
\text { major and minor }\end{array}$ & 5.9 & $113,160,76$ \\
\hline $\mathrm{AD}$ & $\mathrm{HC}<\mathrm{PD}$ & 8520 & $\begin{array}{l}\text { Bilateral ATR, CST, IFOF, UF, ALIC, ACR, SCR, external capsule, SFOF; } \\
\text { Lt-PLIC; Rt-SLF, PCR, retrolenticular part of the IC, fornix; genu and body of } \\
\text { CC, forceps minor }\end{array}$ & 5.49 & $113,160,76$ \\
\hline $\mathrm{RD}$ & $\mathrm{HC}<\mathrm{PD}$ & 54131 & $\begin{array}{l}\text { Bilateral ATR, CST, CgH, IFOF, ILF, SLF, UF, temporal part of the SLF, medial } \\
\text { lemniscus, ICP, SCP, ALIC, PLIC, retrolenticular part of the IC, ACR, SCR, } \\
\text { PCR, PTR, sagittal stratum, external capsule, SFOF, tapatum; Lt-CCG; genu, } \\
\text { body and splenium of CC, fornix, forceps major and minor and MCP }\end{array}$ & 5.95 & $121,106,64$ \\
\hline $\mathrm{FA}_{\mathrm{T}}$ & $\mathrm{HC}>\mathrm{PD}$ & 22185 & $\begin{array}{c}\text { Bi-tensor FW imaging } \\
\text { Bilateral ATR, CST, IFOF, ILF, SLF, ACR, SCR, PCR, external capsule; Lt-CCG, } \\
\text { UF, retrolenticular part of the IC, PTR, sagittal stratum; forceps major and } \\
\text { minor, genu, body and splenium of CC, fornix }\end{array}$ & 5.37 & $45,125,47$ \\
\hline $\mathrm{MD}_{\mathrm{T}}$ & $\mathrm{HC}<\mathrm{PD}$ & 18356 & $\begin{array}{l}\text { Bilateral ATR, CST, IFOF, SLF, UF, ALIC, PLIC, ACR, SCR, external capsule, } \\
\text { SFOF; Lt-CCG, retrolenticular part of the IC, PCR; forceps minor, genu, body } \\
\text { and splenium of CC; fornix }\end{array}$ & 5.73 & $119,94,120$ \\
\hline $\mathrm{AD}_{\mathrm{T}}$ & $\mathrm{HC}<\mathrm{PD}$ & 11610 & $\begin{array}{l}\text { Bilateral ATR, CST, IFOF, UF, ALIC, PLIC, retrolenticular part of the IC, ACR, } \\
\text { SCR, PCR, external capsule, SFOF; Rt- SLF; genu, body and splenium of the } \\
\text { CC and forceps minor }\end{array}$ & 5.52 & $80,158,77$ \\
\hline $\mathrm{RD}_{\mathrm{T}}$ & $\mathrm{HC}<\mathrm{PD}$ & 33504 & $\begin{array}{l}\text { Bilateral ATR, CST, IFOF, ILF, SLF, UF, ALIC, PLIC, ACR, SCR, PCR, PTR, } \\
\text { sagittal stratum, external capsule, SFOF; Lt-CCG; temporal part of the Rt-SLF, } \\
\text { retrolenticular part of the IC, UF, tapatum; forceps major and minor, genu, } \\
\text { body and splenium of CC, fornix }\end{array}$ & 5.64 & $143,99,99$ \\
\hline FW & $\mathrm{HC}<\mathrm{PD}$ & 5716 & $\begin{array}{l}\text { Bilateral ATR, CST, IFOF, ILF, SLF, SLF temporal part, SCR, PCR, PTR, } \\
\text { tapatum; Lt-retrolenticular part of the IC, sagittal stratum; Rt-ACR; forceps } \\
\text { major and minor, genu, body and splenium of CC, fornix }\end{array}$ & 5.45 & $89,133,74$ \\
\hline
\end{tabular}




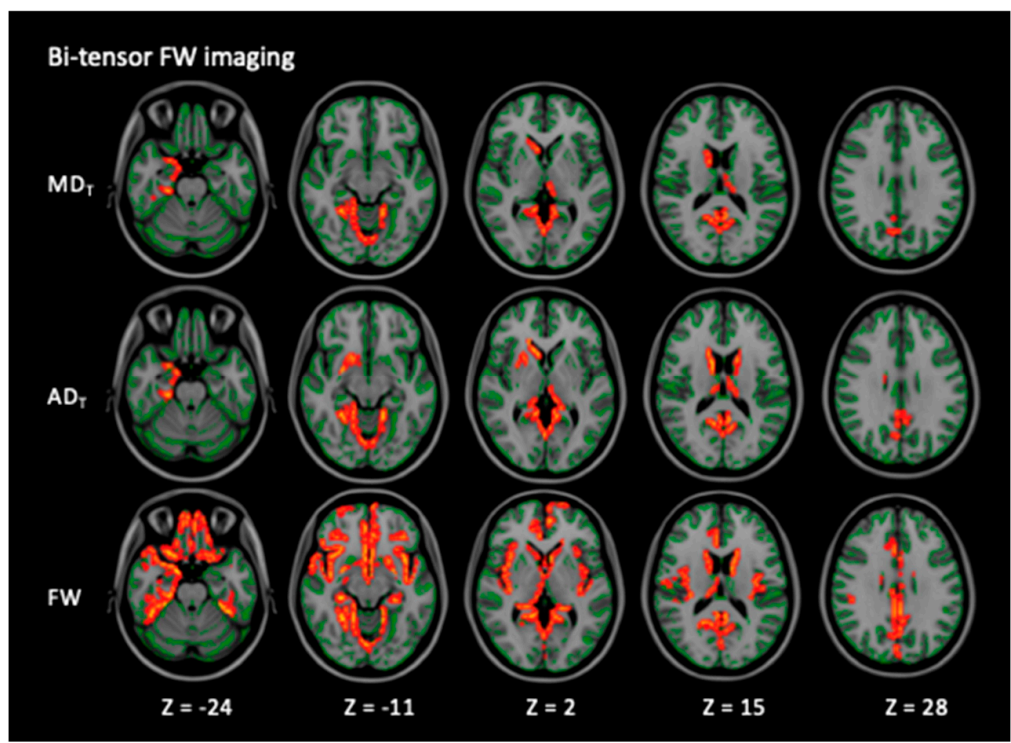

Figure 2. Comparison of $\mathrm{FW}$ imaging $\left(\mathrm{MD}_{\mathrm{T}}, \mathrm{AD}_{\mathrm{T}}\right.$, and $\left.\mathrm{FW}\right)$ indices between the healthy controls and the patients with PD. GBSS analyses showed that the patients with PD had significantly higher $\mathrm{MD}_{\mathrm{T}}, \mathrm{AD}_{\mathrm{T}}$, and FW (red-yellow voxels) compared with the healthy controls ( $p<0.05$, FWE-corrected). The skeleton is presented in green. To aid visualization, the results are thickened using the fill script implemented in the FMRIB Software Library. $\mathrm{AD}$, axial diffusivity; $\mathrm{AD}_{\mathrm{T}}, \mathrm{FW}$-corrected axial diffusivity; FW, free water; GBSS, gray matter-based spatial statistics; $\mathrm{MD}$, mean diffusivity; $\mathrm{MD}_{\mathrm{T}}$, $\mathrm{FW}$-corrected mean diffusivity; PD, Parkinson's disease.

Table 3. Region-of-interest analysis of diffusion tensor and free-water imaging indices in the white matter of Parkinson's disease patients and healthy controls.

\begin{tabular}{|c|c|c|c|c|c|c|c|c|}
\hline & \multirow{2}{*}{$\begin{array}{l}\text { WM } \\
\text { Areas }\end{array}$} & \multicolumn{2}{|c|}{ HC } & \multirow{2}{*}{$\begin{array}{c}\text { PD } \\
\text { Mean }\end{array}$} & \multirow[b]{2}{*}{ SD } & \multirow{2}{*}{$P$ Value } & \multirow{2}{*}{$t$-Value } & \multirow{2}{*}{$\begin{array}{c}\text { Cohen's } \\
d\end{array}$} \\
\hline & & Mean & SD & & & & & \\
\hline \multicolumn{9}{|c|}{ DTI } \\
\hline \multirow[t]{2}{*}{ FA } & Anterior & 0.48 & 0.014 & 0.47 & 0.018 & 0.019 * & 2.46 & 0.78 \\
\hline & Posterior & 0.61 & 0.021 & 0.60 & 0.021 & 0.011 * & 2.69 & 0.85 \\
\hline \multirow[t]{2}{*}{ MD } & Anterior & 0.80 & 0.035 & 0.83 & 0.048 & 0.014 * & -2.58 & 0.81 \\
\hline & Posterior & 0.82 & 0.029 & 0.85 & 0.047 & $0.036^{\circ}$ & -2.18 & 0.69 \\
\hline \multirow[t]{2}{*}{$\mathrm{AD}$} & Anterior & 1.25 & 0.043 & 1.28 & 0.058 & $0.038^{\circ}$ & -2.16 & 0.68 \\
\hline & Posterior & 1.49 & 0.038 & 1.51 & 0.058 & 0.32 & -1.00 & 0.32 \\
\hline \multirow[t]{2}{*}{ RD } & Anterior & 0.57 & 0.032 & 0.61 & 0.046 & 0.010 * & -2.71 & 0.86 \\
\hline & Posterior & 0.49 & 0.032 & 0.52 & 0.045 & 0.012 * & -2.65 & 0.84 \\
\hline \multicolumn{9}{|c|}{ FW imaging } \\
\hline \multirow[t]{2}{*}{$\mathbf{F A}_{\mathbf{T}}$} & Anterior & 0.64 & 0.026 & 0.61 & 0.020 & 0.0021 * & 3.30 & 1.04 \\
\hline & Posterior & 0.75 & 0.018 & 0.75 & 0.019 & 0.40 & 0.85 & 0.27 \\
\hline \multirow[t]{2}{*}{$\mathrm{MD}_{\mathrm{T}}$} & Anterior & 0.56 & 0.039 & 0.60 & 0.036 & 0.0014 * & -3.45 & 1.09 \\
\hline & Posterior & 0.61 & 0.014 & 0.62 & 0.022 & 0.25 & -1.16 & 0.37 \\
\hline \multirow[t]{2}{*}{$\mathrm{AD}_{\mathrm{T}}$} & Anterior & 1.00 & 0.053 & 1.05 & 0.053 & 0.0025 * & -3.24 & 1.02 \\
\hline & Posterior & 1.29 & 0.027 & 1.29 & 0.041 & 0.71 & -0.38 & 0.12 \\
\hline \multirow[t]{2}{*}{$\mathbf{R D}_{\mathrm{T}}$} & Anterior & 0.34 & 0.033 & 0.37 & 0.031 & 0.0016 * & -3.40 & 1.22 \\
\hline & Posterior & 0.27 & 0.020 & 0.28 & 0.024 & 0.26 & -1.14 & 0.36 \\
\hline \multirow[t]{2}{*}{ FW } & Anterior & 0.21 & 0.016 & 0.23 & 0.042 & 0.079 & -1.81 & 0.57 \\
\hline & Posterior & 0.21 & 0.024 & 0.24 & 0.042 & 0.020 * & -2.44 & 0.77 \\
\hline
\end{tabular}

$\mathrm{AD}$, axial diffusivity; $\mathrm{AD}_{\mathrm{T}}$, free water-corrected axial diffusivity; $\mathrm{DTI}$, diffusion tensor imaging; $\mathrm{FA}$, fractional anisotropy; $\mathrm{FA}_{\mathrm{T}}$, free water-corrected fractional anisotropy; $\mathrm{FW}$, free water; HC, healthy control; $\mathrm{MD}$, mean diffusivity; $\mathrm{MD}_{\mathrm{T}}$, free water-corrected mean diffusivity; $\mathrm{PD}$, Parkinson's disease; $\mathrm{RD}$, radial diffusivity; $\mathrm{RD}_{\mathrm{T}}$, free water-corrected radial diffusivity; SD, standard deviation; WM, white matter. ${ }^{*} p \leq 0.025$; $^{\circ} 0.025<p<0.05$. 


\subsection{GM Alterations}

\subsubsection{GBSS}

Figure 3 and Table 4 show the GBSS analysis results of $\mathrm{MD}_{\mathrm{T}}, \mathrm{AD}_{\mathrm{T}}$, and FW. The patients with PD exhibited significantly higher $\mathrm{MD}_{\mathrm{T}}, \mathrm{AD}_{\mathrm{T}}$, and $\mathrm{FW}(p<0.05$, FWE-corrected) indices compared with the healthy controls. The details regarding the anatomical region, peak $t$-value, and peak MNI coordinates of significant clusters are presented in Table 4 . No significant differences in any of the DTI indices, FA T or $\mathrm{RD}_{\mathrm{T}}$ were found between the patients with $\mathrm{PD}$ and the healthy controls. There were no significant differences in the DTI and FW imaging indices between the patients with right-sided and left-sided onset PD, the healthy controls and the patients with right-sided onset PD, or the healthy controls and the patients with left-sided onset PD.
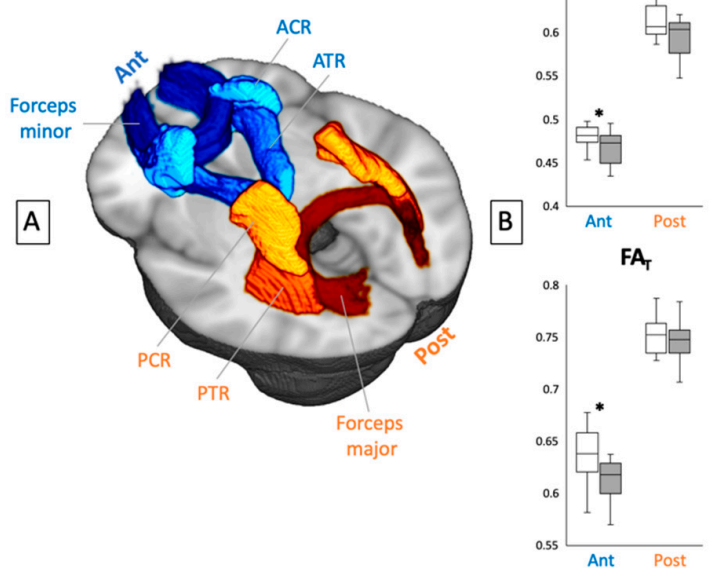
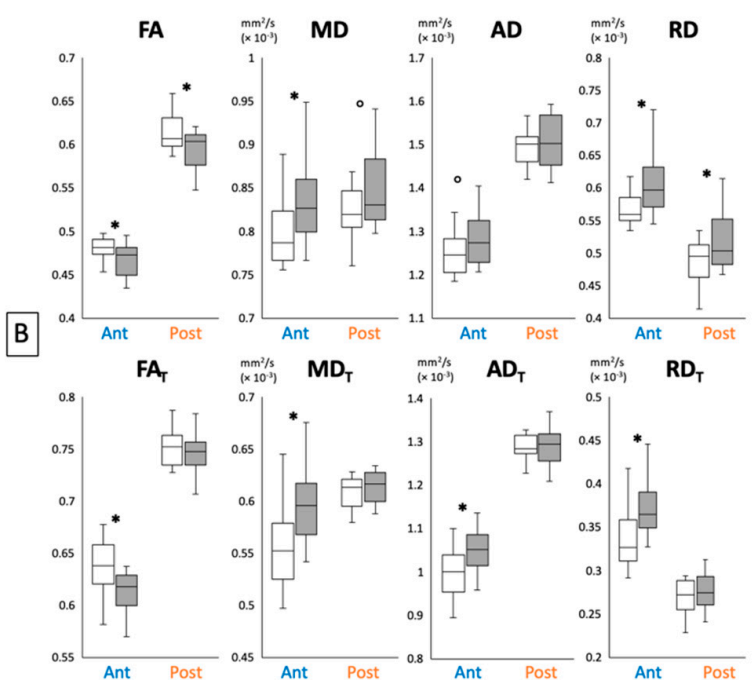
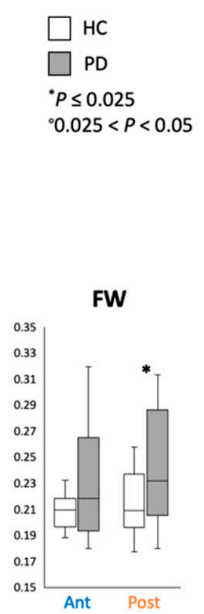

Figure 3. (A) Region-of-interest analyses of the anterior (ACR, ATR, and forceps minor) and posterior (PCR, PTR, and forceps major) white matter areas. (B) Mean values for DTI (FA, MD, AD, and RD) and $\mathrm{FW}$ imaging $\left(\mathrm{FA}_{\mathrm{T}}, \mathrm{MD}_{\mathrm{T}}, \mathrm{AD}_{\mathrm{T}}, \mathrm{RD}_{\mathrm{T}}\right.$, and $\left.\mathrm{FW}\right)$ indices of the anterior and posterior white matter areas in healthy controls (white bars) and patients with $\mathrm{PD}$ (gray bars). ACR, anterior corona radiata; AD, axial diffusivity, $\mathrm{AD}_{\mathrm{T}}$, FW-corrected axial diffusivity; $\mathrm{ATR}$, anterior thalamic radiation; DTI, diffusion tensor imaging; $\mathrm{FA}$, fractional anisotropy; $\mathrm{FA}_{\mathrm{T}}$, free water-corrected fractional anisotropy; $\mathrm{FW}$, free water; $\mathrm{HC}$, healthy controls; $\mathrm{MD}$, mean diffusivity; $\mathrm{MD}_{\mathrm{T}}$, free water-corrected mean diffusivity; $\mathrm{PCR}$, posterior corona radiata; PD, Parkinson's disease; PTR, posterior thalamic radiation; $R D$, radial diffusivity; $\mathrm{RD}_{\mathrm{T}}$, free water-corrected radial diffusivity. 
Table 4. Gray-matter-based spatial statistics analysis of free-water imaging indices in patients with Parkinson's disease and healthy controls.

\begin{tabular}{|c|c|c|c|c|c|c|}
\hline Modality & Contrast & $\begin{array}{l}\text { Cluster } \\
\text { Size }\end{array}$ & & Anatomical Region & Peak $t$-Value & $\begin{array}{c}\text { Peak MNI } \\
\text { Coordinates }(X, Y, Z)\end{array}$ \\
\hline \multirow[t]{7}{*}{$\mathrm{MD}_{\mathrm{T}}$} & $\mathrm{HC}<\mathrm{PD}$ & & & & 4.9 & $38,60,46$ \\
\hline & & - & Frontal & - & & \\
\hline & & 42 & Temporal & Bilateral fusiform, Rt-entorhinal and temporal pole & & \\
\hline & & 43 & Parietal & Bilateral precuneus & & \\
\hline & & 23 & Occipital & Bilateral lingual & & \\
\hline & & 102 & Limbic and & Bilateral isthmus cingulate and para-hippocampal; & & \\
\hline & & 49 & Deep GM & Lt-thalamus; Rt-caudate and putamen & & \\
\hline \multirow[t]{8}{*}{$\mathrm{AD}_{\mathrm{T}}$} & $\mathrm{HC}<\mathrm{PD}$ & & & & 5.05 & $38,60,46$ \\
\hline & & - & Frontal & - & & \\
\hline & & 62 & Temporal & $\begin{array}{l}\text { Bilateral fusiform; Rt-enthorinal, inferior temporal } \\
\text { and temporal pole }\end{array}$ & & \\
\hline & & 53 & Parietal & Bilateral precuneus & & \\
\hline & & 27 & Occipital & Bilateral lingual & & \\
\hline & & & Limbic and & Bilateral isthmus cingulate, para-hippocampal and & & \\
\hline & & 146 & para-limbic & hippocampus; Rt-amygdala and accumbens & & \\
\hline & & 162 & Deep GM & Bilateral thalamus, caudate; Rt-putamen & & \\
\hline \multirow[t]{7}{*}{ FW } & $\mathrm{HC}<\mathrm{PD}$ & & & & 7.37 & $43,46,54$ \\
\hline & & 534 & Frontal & $\begin{array}{l}\text { Bilateral lateral orbitofrontal, medial orbitofrontal, } \\
\text { pars opercularis, pars orbitalis, pars triangularis, } \\
\text { superior frontal, frontal pole and precentral; } \\
\text { Rt-paracentral and rostral middle frontal } \\
\text { Bilateral fusiform and superior temporal; }\end{array}$ & & \\
\hline & & 235 & Temporal & $\begin{array}{l}\text { Lt-transverse temporal; Rt-entorhinal, fusiform, } \\
\text { inferior temporal and temporal pole }\end{array}$ & & \\
\hline & & 132 & Parietal & Bilateral post-central, precuneus; Rt-supramarginal & & \\
\hline & & 47 & Occipital & $\begin{array}{c}\text { Bilateral lingual; Lt-cuneus, lateral-occipital and } \\
\text { pericalcarine }\end{array}$ & & \\
\hline & & 1106 & $\begin{array}{l}\text { Limbic and } \\
\text { para-limbic }\end{array}$ & $\begin{array}{l}\text { Bilateral isthmus cingulate, caudal anterior } \\
\text { cingulate, posterior cingulate, rostral anterior } \\
\text { cingulate, insula, para-hippocampal, accumbens } \\
\text { and hippocampus; Rt-amygdala }\end{array}$ & & \\
\hline & & 133 & Deep GM & Bilateral thalamus, caudate and putamen & & \\
\hline
\end{tabular}

$\mathrm{Lt}$, left; Rt, right; $\mathrm{AD}_{\mathrm{T}}$, free water-corrected axial diffusivity; $\mathrm{FW}$, free water; $\mathrm{GM}$, gray matter; $\mathrm{HC}$, healthy controls; $\mathrm{MD}_{\mathrm{T}}$, free water-corrected mean diffusivity; $\mathrm{PD}$, Parkinson's disease. 


\subsubsection{ROI}

Figure 4 and Table 5 show the ROI analysis results for $\mathrm{MD}_{\mathrm{T}}, \mathrm{AD}_{\mathrm{T}}$, and $\mathrm{FW}$ in $\mathrm{GM}$ areas corresponding to Braak stages IV-VI. The patients with PD demonstrated significantly higher $\mathrm{MD}_{\mathrm{T}}$ and FW and tended to have higher $\mathrm{AD}_{\mathrm{T}}$ compared with the healthy controls in the areas corresponding to Braak stage IV. Among the Braak stage V areas, the patients with PD tended to have higher $\mathrm{MD}_{\mathrm{T}}, \mathrm{AD}_{\mathrm{T}}$, and FW compared with the healthy controls. No significant differences in GM were found between the patients with PD and healthy controls within the areas corresponding to Braak stage VI.

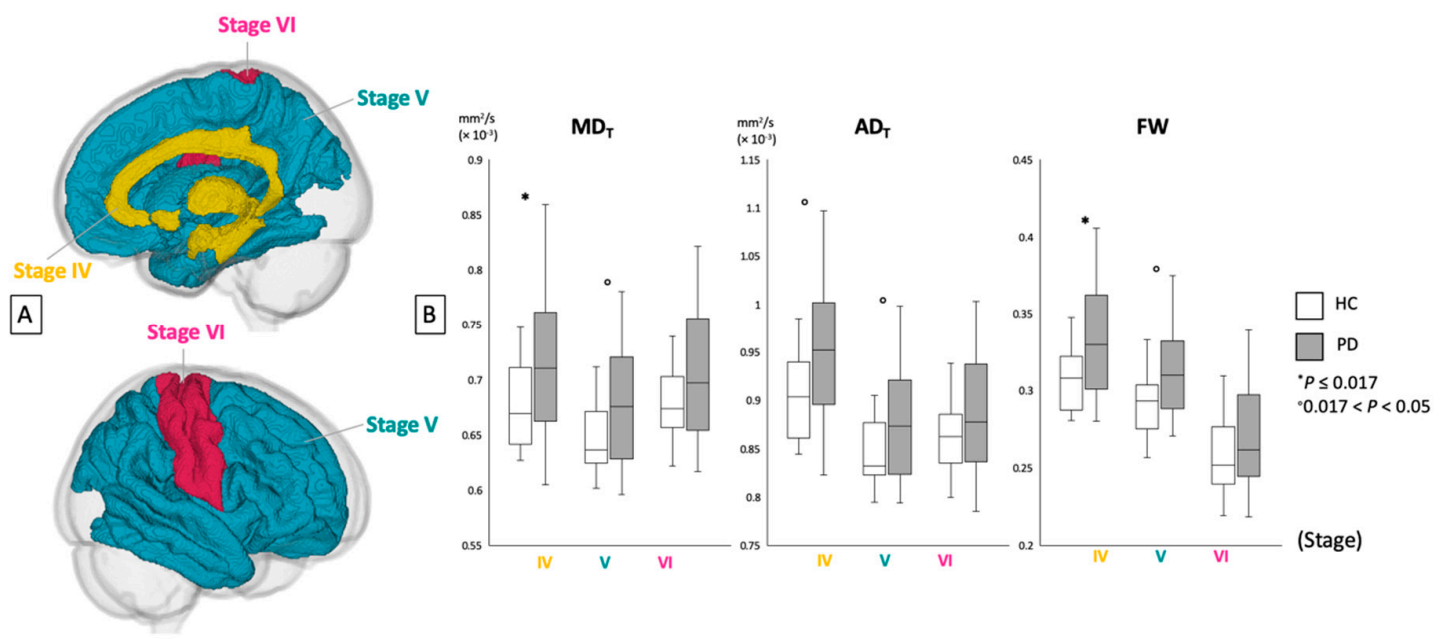

Figure 4. (A) Region-of-interest analyses of gray matter areas belonging to Braak stages IV, V, and VI. (B) Mean values for $\mathrm{FW}$ imaging indices $\left(\mathrm{MD}_{\mathrm{T}}, \mathrm{AD}_{\mathrm{T}}\right.$, and $\mathrm{FW}$ ) of each area in healthy controls (white bars) and patients with $\mathrm{PD}$ (gray bars). $\mathrm{AD}_{\mathrm{T}}$, free water-corrected axial diffusivity; FW, free water; $\mathrm{HC}$, healthy controls; $\mathrm{MD}_{\mathrm{T}}$, free water-corrected mean diffusivity; $\mathrm{PD}$, Parkinson's disease.

Table 5. Region-of-interest analyses of free-water imaging indices in the gray matter of patients with Parkinson's disease and healthy controls according to the Braak staging.

\begin{tabular}{|c|c|c|c|c|c|c|c|c|}
\hline & \multirow{2}{*}{$\begin{array}{l}\text { Braak } \\
\text { Stage }\end{array}$} & \multirow{2}{*}{$\begin{array}{c}\text { HC } \\
\text { Mean }\end{array}$} & \multicolumn{3}{|c|}{ PD } & \multirow{2}{*}{$P$ Value } & \multirow{2}{*}{$t$-Value } & \multirow{2}{*}{$\begin{array}{c}\text { Cohen's } \\
d\end{array}$} \\
\hline & & & SD & Mean & SD & & & \\
\hline \multirow[t]{3}{*}{$\mathbf{M D}_{\mathrm{T}}$} & IV & 0.56 & 0.039 & 0.60 & 0.036 & $0.016^{*}$ & -2.51 & 0.79 \\
\hline & $\mathrm{V}$ & 0.61 & 0.014 & 0.62 & 0.022 & $0.036^{\circ}$ & -2.18 & 0.69 \\
\hline & VI & 0.34 & 0.033 & 0.37 & 0.031 & 0.073 & -1.85 & 0.35 \\
\hline \multirow[t]{3}{*}{$\mathrm{AD}_{\mathrm{T}}$} & IV & 0.90 & 0.043 & 0.95 & 0.078 & $0.018^{\circ}$ & -2.48 & 0.78 \\
\hline & $\mathrm{V}$ & 0.84 & 0.032 & 0.88 & 0.059 & $0.044^{\circ}$ & -2.08 & 0.66 \\
\hline & VI & 0.86 & 0.037 & 0.88 & 0.064 & 0.20 & -1.30 & 0.41 \\
\hline \multirow[t]{3}{*}{ FW } & VI & 0.31 & 0.020 & 0.33 & 0.037 & 0.0059 * & -2.92 & 0.92 \\
\hline & $\mathrm{V}$ & 0.29 & 0.020 & 0.31 & 0.030 & $0.021^{\circ}$ & -2.41 & 0.76 \\
\hline & VI & 0.26 & 0.025 & 0.27 & 0.036 & 0.13 & -1.56 & 0.49 \\
\hline
\end{tabular}

$\mathrm{AD}_{\mathrm{T}}$, free water-corrected axial diffusivity; DTI, diffusion tensor imaging; FW, free water; HC, healthy controls; $\mathrm{MD}_{\mathrm{T}}$, free water-corrected mean diffusivity; PD, Parkinson's disease; ROI, region of interest; $\mathrm{SD}$, standard deviation. * $p \leq 0.025 ;{ }^{\circ} 0.025<p<0.05$.

\subsection{WM and GM Volumetry}

Morphometry analysis revealed no focal volumetric differences between the patients with PD and the healthy controls. 


\subsection{Correlation Analysis}

Both the voxel-wise and the ROI analyses showed no significant correlations between the indices and the disease duration or clinical scores measured using UPDRS part I score, UPDRS part I subscores, and UPDRS part III score.

\section{Discussion}

In the present study, we investigated WM and GM alterations by comparing the patients with PD to the healthy controls using DTI and FW images. In the TBSS analysis, the changes in the FW imaging indices (increased $\mathrm{FW}$ and reduced $\mathrm{FA}_{\mathrm{T}}$ and increased $\mathrm{MD}_{\mathrm{T}}, \mathrm{AD}_{\mathrm{T}}$, and $\mathrm{RD}_{\mathrm{T}}$ ) were in somewhat more specific WM areas compared with the changes in DTI indices (reduced FA and increased MD, AD, and $\mathrm{RD}$ ). These findings are further supported by our ROI analysis to specifically analyze the WM tracts running through the anterior and posterior portions of the brain. The significantly reduced $F A_{T}$ and the significantly increased $\mathrm{MD}_{\mathrm{T}}, \mathrm{AD}_{\mathrm{T}}$, and $\mathrm{RD}_{\mathrm{T}}$ were observed only in the anterior $\mathrm{WM}$ tracts with a higher effect size than the DTI indices; the increased FW was observed only in the posterior WM tracts of the patients with PD. Furthermore, in the GBSS analysis, increases in $\mathrm{MD}_{\mathrm{T}}, \mathrm{AD}_{\mathrm{T}}$, and FW were observed in the GM of the patients with $\mathrm{PD}$, whereas no significant differences were found in any of the DTI indices. The ROI analysis demonstrated that the changes in these measures corresponded with Braak stage IV.

In the WM, the observed increase in increased FW, which is expected during neuroinflammation [32], is in line with the reported inflammatory processes related to the activation of astrocytes and microglia, which are linked to $\alpha$-synuclein aggregation, in PD [33]. Furthermore, the reduced $F A_{T}$ and increased $M D_{T}, A D_{T}$, and $\mathrm{RD}_{\mathrm{T}}$, which usually result from axonal damage and demyelination [4], might be the result of the aggregation of Lewy neurites that are associated with impaired axonal transport with subsequent microstructural changes in the axon and surrounding myelin [11]. The current study also demonstrated that the FW indices were able to derive more precise estimations of localized WM degeneration in PD compared with the DTI indices. An explanation might be that partialling out FW eliminated the influence of CSF on WM tracts running closely adjacent to the ventricles and brain pathologies such as neuroinflammation, thereby increasing the specificity of FW imaging indices $[7,8]$. Thus, the current results suggest that the changes in the DTI indices within the posterior WM tracts of the patients with PD were largely influenced by neuroinflammation. In line with the current results, a study on patients with schizophrenia reported changes in DTI indices in specific areas after excluding the influence of extracellular FW [8]. Furthermore, a study recently demonstrated the correlation between FW obtained using FW imaging and the 18-kDa translocator protein (TSPO), using positron emission tomography with $\left[{ }^{11} \mathrm{C}\right] \mathrm{DPA}-713$ that binds TSPO, in patients with traumatic brain injury [34].

Anterior brain has been suggested to be more prone to Lewy pathology than posterior brain $[35,36]$. The prefrontal cortex is an area where Lewy pathology occurs at a relatively early stage of PD [11]. Additionally, PD is considered to be a prion-like disorder where misfolded $\alpha$-synuclein spreads from one neuron to another from the anterior to the posterior along WM [26]. Given that most of the current study patients (85\%) were in Hoehn and Yahr stage 2, it is possible that, at the time of the examination, the Lewy neurites had progressed from the anterior portions to reach the posterior portions of the brain, with simultaneous neurodegeneration induced by neuroinflammation in the anterior portions. Taken together, the current results demonstrated that the microstructural changes in the WM of patients with PD were preceded by neuroinflammation and followed by neurodegeneration. These findings are supported by the previously demonstrated exacerbation of dopaminergic neurodegeneration in the substantia nigra pars compacta by the chronic release of pro-inflammatory cytokines [33]. Moreover, animal models of PD demonstrated that Lewy pathology triggered reactive microgliosis prior to nigral degeneration [2].

Increased $\mathrm{MD}_{\mathrm{T}}, \mathrm{AD}_{\mathrm{T}}$, and $\mathrm{FW}$, which are indicative of axonal degeneration and neuroinflammation [4,32], in the GM of patients with PD, were demonstrated using GBSS analysis. 
The lack of significant differences in the DTI indices in GM suggests that the FW imaging indices provided greater sensitivity in the detection of GM abnormalities in the patients with PD. DTI is not the preferred method for the evaluation of GM, especially the cortex, other than the substantia nigra and striatum, mainly because of its inability to thoroughly describe microstructural abnormalities in GM due to water diffusion isotropy [37]. Furthermore, the use of diffusion MRI for the evaluation of GM, especially cortical areas, has been limited by the partial volume effect of the WM and CSF adjacent to the cortical GM [38]. FW imaging removes the isotropic FW compartment in the GM, thus leading to a more anisotropic estimation of the single tensor in one voxel [39]. In the present study, the partial volume effect of the WM and CSF was further minimized using GBSS analysis. In line with a previous study [28], the current results demonstrated that GBSS analysis enables the regional characterization of GM pathology in PD because GBSS analysis involves the aggregation of diffusion MRI indices in regions surrounding the skeleton created at the center of the cortical GM, thus minimizing the partial volume effect [22].

Unlike the widespread microstructural changes observed in WM, the GBSS results identified significant changes within more limited GM areas in the patients with PD. Furthermore, no significant difference in $\mathrm{FA}_{\mathrm{T}}$ of the GM was observed between the patients with PD and the healthy controls. Decreases in GM FA, an index of neuron integrity, was previously reported to appear later than increases in MD during the progression of PD [40]. Taken together, the current results indicate that WM microstructural changes in PD occur early and may precede changes in GM. Our findings agree with those of previous studies that reported widespread changes in WM microstructure in patients with early PD with no or limited GM alteration [41-43]. These results are also consistent with a recent hypothesis regarding pathological progression in $\mathrm{PD}$, wherein pre-synaptic terminal damage, impaired axonal transport, and/or altered axonal structure precede cell body damage, otherwise known as the "dying back" pattern of degeneration [44]. In addition, the changes in FW imaging measures were also demonstrated in the thalamus areas. Previous histopathological and imaging studies demonstrated the involvement of thalamus in PD patients with RBD $[45,46]$. Thus, the microstructural changes of the thalamus might be related to RBD in patients with PD.

Furthermore, the ROI analyses in the present study indicated that the most striking difference in the extent and the distribution of GM damage, specifically, neuroinflammation (indexed by FW) and axonal degeneration (indexed by $\mathrm{MD}_{\mathrm{T}}$ and $\mathrm{AD}_{\mathrm{T}}$ ) [4,32], corresponded with Braak stage IV. At Braak stage III, patients with PD exhibit typical features described in Hoehn and Yahr stage 1 (i.e., tremors, rigidity, and bradykinesia) typically on one side of the body [47]. However, as the disease enters Braak stage IV, the clinical features become bilateral (Hoehn and Yahr stage 2). Considering that $85 \%$ of the participants in the present study were in Hoehn and Yahr stage 2, the study findings agree with the neuropathological and clinical patterns of PD. Additionally, among the changes in $\mathrm{MD}_{\mathrm{T}}, \mathrm{AD}_{\mathrm{T}}$, and FW, FW showed the strongest effect size. This finding, along with that for WM, also suggest that neuroinflammation may be preceding axonal degeneration in the GM of patients with PD.

No differences in the WM and GM volumes were observed between the patients with PD and healthy controls. The current study results support the conclusions from several studies wherein no volume changes were detected in early PD $[28,42]$, suggesting that volumetric alterations in brain structures may occur later in the disease course, as described in studies on advanced PD [41]. This finding also lends further support for the suggestion that diffusion MRI indices are potentially more sensitive as biomarkers for detecting microstructural changes in PD prior to tissue loss detected during volumetric MRI.

None of the indices included herein correlated with disease duration. This finding is consistent with those of histopathological studies showing that the aggregation of Lewy pathology occurs before the appearance of symptoms [48]. However, medication effects may also explain the observed lack of correlation with the scores of UPDRS parts I and III [49]. Zhang et al. [50] and Wen et al. [51] previously reported a correlation between DTI indices and the scores of UPDRS part III in the brains of untreated patients with PD. In contrast, we [52] and another group [49] showed a lack of such correlation in the 
brains of treated patients with PD. Furthermore, one study demonstrated that the UPDRS lacks the sensitivity to discriminate the severity of symptoms of early PD [53].

Some limitations of the present study should be noted. First, the small sample size limits the statistical power, which may have led to the nonsignificant results in some measures including correlation analysis. Second, this was a case-control study. Third, although the patients with PD in the current study were defined to be Hoehn and Yahr stage 1-2, most of the patients were in Hoehn and Yahr stage 2. Further studies including patients with preclinical or earlier-stage PD and longitudinal studies involving larger cohorts will be particularly informative in clarifying the utility of FW indices as biomarkers for diagnosis and disease progression and in resolving the temporal sequence of events of neuroinflammation and neurodegeneration. Fourth, the current study lacked histopathological verification. Future studies should also include TSPO-positron emission tomography imaging to verify neuroinflammation in PD. Fifth, in the current study, we did not categorize the patients with PD based on the clinical PD phenotypes such as non-tremor and tremor-dominant subtypes, whereas motor phenotypes in PD are recognized to have a distinct neural basis [54], which should be considered for further investigation as well. Sixth, we did not specifically evaluate patients with PD based on clinical symptoms such as RBD or hyposmia. Additionally, polysomnography [55] and the odor stick identification test [56], objective assessments that confirm the clinical diagnosis of RBD and hyposmia, respectively, were not performed in the patients with PD. However, considering that both symptoms appear early and are common in PD, further studies should be conducted with objective evaluation focusing on these symptoms. Studies investigating microstructural changes in patients with RBD, de novo PD, and PD with RBD, using FW imaging will also be crucial for a better understanding of the pathology underlying PD. Finally, TBSS and GBSS lack the sensitivity to detect peripheral effects located outside the skeleton, and the skeleton projection step may also introduce bias to the projected parameters.

\section{Conclusions}

The current study results provide novel evidence that FW imaging in PD may be useful in determining the etiology of microstructural changes, more specifically related to neurodegeneration and neuroinflammation. Furthermore, FW imaging provided more precise estimations of localized microstructural changes in PD compared with DTI. These findings also demonstrated that neuroinflammation preceded neurodegeneration in $\mathrm{PD}$, whereas changes in the WM microstructure preceded those in the GM. However, considering the limitations of the current study, the findings should be clinically interpreted with caution. Particularly, longitudinal studies and histopathological verification are necessary to validate the current study findings.

Author Contributions: C.A., K.K., T.H., A.S., T.O., H.T-A., and A.Z. contributed to the conception and design of the study. W.U., A.W., M.S., A.H., R.I., K.K.K., G.O., Y.S., and A.U. contributed to the data collection and acquisition and analysis of data. C.A., K.K., T.H., W.U., M.H., C.P., N.H., and S.A. contributed to drafting the text and preparing the figures. All authors have reviewed and approved the contents of the manuscript.

Funding: S.A. was supported by Brain/MINDS program from the Japan Agency for Medical Research and Development (AMED); JSPS KAKENHI Grant Number 18H02772 and JP16H06280; and a Grant-in-Aid for Special Research in Subsidies for ordinary expenses of private schools from The Promotion and Mutual Aid Corporation for Private Schools of Japan. K.K. was supported by Brain/MINDS Beyond program from AMED (JP19dm0307024); JSPS KAKENHI (19K17244). C.P. was supported by a National Health \& Medical Research Council (NHMRC) Senior Principal Research Fellowship (1105825). A.Z. was supported by the Australian National Health and Medical Research Council (NHMRC) Senior Research Fellowship B (1136649).

Acknowledgments: We thank Yuki Takenaka and Mana Kuramochi for their research assistance. We also thank all patients and healthy controls who participated in this study.

Conflicts of Interest: The authors declare no conflicts of interest. 


\section{References}

1. Recasens, A.; Dehay, B. Alpha-synuclein spreading in Parkinson's disease. Front. Neuroanat. 2014, 8, 159. [CrossRef] [PubMed]

2. Duffy, M.F.; Collier, T.J.; Patterson, J.R.; Kemp, C.J.; Luk, K.C.; Tansey, M.G.; Paumier, K.L.; Kanaan, N.M.; Fischer, D.L.; Polinski, N.K.; et al. Lewy body-like alpha-synuclein inclusions trigger reactive microgliosis prior to nigral degeneration. J. Neuroinflamm. 2018, 15, 129. [CrossRef] [PubMed]

3. Atkinson-Clement, C.; Pinto, S.; Eusebio, A.; Coulon, O. Diffusion tensor imaging in Parkinson's disease: Review and meta-analysis. Neuroimage Clin. 2017, 16, 98-110. [CrossRef] [PubMed]

4. Alexander, A.L.; Lee, J.E.; Lazar, M.; Field, A.S. Diffusion tensor imaging of the brain. Neurotherapeutics 2007, 4, 316-329. [CrossRef] [PubMed]

5. Assaf, Y.; Pasternak, O. Diffusion tensor imaging (DTI)-based white matter mapping in brain research: A review. J. Mol. Neurosci. 2008, 34, 51-61. [CrossRef] [PubMed]

6. Metzler-Baddeley, C.; O'Sullivan, M.J.; Bells, S.; Pasternak, O.; Jones, D.K. How and how not to correct for CSF-contamination in diffusion MRI. Neuroimage 2012, 59, 1394-1403. [CrossRef] [PubMed]

7. Pasternak, O.; Sochen, N.; Gur, Y.; Intrator, N.; Assaf, Y. Free water elimination and mapping from diffusion MRI. Magn. Reson. Med. 2009, 62, 717-730. [CrossRef] [PubMed]

8. Oestreich, L.K.L.; Lyall, A.E.; Pasternak, O.; Kikinis, Z.; Newell, D.T.; Savadjiev, P.; Bouix, S.; Shenton, M.E.; Kubicki, M.; Australian Schizophrenia Research Bank; et al. Characterizing white matter changes in chronic schizophrenia: A free-water imaging multi-site study. Schizophr. Res. 2017, 189, 153-161. [CrossRef] [PubMed]

9. Chan, L.L.; Rumpel, H.; Yap, K.; Lee, E.; Loo, H.V.; Ho, G.L.; Fook-Chong, S.; Yuen, Y.; Tan, E.K. Case control study of diffusion tensor imaging in Parkinson's disease. J. Neurol. Neurosurg. Psychiatry 2007, 78, 1383-1386. [CrossRef]

10. Yoshikawa, K.; Nakata, Y.; Yamada, K.; Nakagawa, M. Early pathological changes in the parkinsonian brain demonstrated by diffusion tensor MRI. J. Neurol. Neurosurg. Psychiatry 2004, 75, 481-484. [CrossRef] [PubMed]

11. Duncan, G.W.; Firbank, M.J.; Yarnall, A.J.; Khoo, T.K.; Brooks, D.J.; Barker, R.A.; Burn, D.J.; O’Brien, J.T. Gray and white matter imaging: A biomarker for cognitive impairment in early Parkinson's disease? Mov. Disord. 2016, 31, 103-110. [CrossRef] [PubMed]

12. Melzer, T.R.; Watts, R.; MacAskill, M.R.; Pitcher, T.L.; Livingston, L.; Keenan, R.J.; Dalrymple-Alford, J.C.; Anderson, T.J. White matter microstructure deteriorates across cognitive stages in Parkinson disease. Neurology 2013, 80, 1841-1849. [CrossRef] [PubMed]

13. Pasternak, O.; Westin, C.F.; Dahlben, B.; Bouix, S.; Kubicki, M. The extent of diffusion MRI markers of neuroinflammation and white matter deterioration in chronic schizophrenia. Schizophr. Res. 2015, 161, 113-118. [CrossRef] [PubMed]

14. Ofori, E.; Pasternak, O.; Planetta, P.J.; Burciu, R.; Snyder, A.; Febo, M.; Golde, T.E.; Okun, M.S.; Vaillancourt, D.E. Increased free water in the substantia nigra of Parkinson's disease: A single-site and multi-site study. Neurobiol. Aging 2015, 36, 1097-1104. [CrossRef] [PubMed]

15. Ofori, E.; Krismer, F.; Burciu, R.G.; Pasternak, O.; McCracken, J.L.; Lewis, M.M.; Du, G.; McFarland, N.R.; Okun, M.S.; Poewe, W.; et al. Free water improves detection of changes in the substantia nigra in parkinsonism: A multisite study. Mov. Disord. 2017, 32, 1457-1464. [CrossRef]

16. Postuma, R.B.; Berg, D.; Stern, M.; Poewe, W.; Olanow, C.W.; Oertel, W.; Obeso, J.; Marek, K.; Litvan, I.; Lang, A.E.; et al. MDS clinical diagnostic criteria for Parkinson's disease. Mov. Disord. 2015, 30, 1591-1601. [CrossRef]

17. Matsuda, H.; Murata, M.; Mukai, Y.; Sako, K.; Ono, H.; Toyama, H.; Inui, Y.; Taki, Y.; Shimomura, H.; Nagayama, H.; et al. Japanese multicenter database of healthy controls for [(123)I]FP-CIT SPECT. Eur. J. Nucl. Med. Mol. Imaging 2018, 45, 1405-1416. [CrossRef]

18. Stebbins, G.T.; Goetz, C.G.; Burn, D.J.; Jankovic, J.; Khoo, T.K.; Tilley, B.C. How to identify tremor dominant and postural instability/gait difficulty groups with the movement disorder society unified Parkinson's disease rating scale: Comparison with the unified Parkinson's disease rating scale. Mov. Disord. 2013, 28, 668-670. [CrossRef] 
19. Postuma, R.B.; Arnulf, I.; Hogl, B.; Iranzo, A.; Miyamoto, T.; Dauvilliers, Y.; Oertel, W.; Ju, Y.E.; Puligheddu, M.; Jennum, P.; et al. A single-question screen for rapid eye movement sleep behavior disorder: A multicenter validation study. Mov. Disord. 2012, 27, 913-916. [CrossRef]

20. Andersson, J.L.; Sotiropoulos, S.N. An integrated approach to correction for off-resonance effects and subject movement in diffusion MR imaging. Neuroimage 2016, 125, 1063-1078. [CrossRef]

21. Smith, S.M.; Jenkinson, M.; Johansen-Berg, H.; Rueckert, D.; Nichols, T.E.; Mackay, C.E.; Watkins, K.E.; Ciccarelli, O.; Cader, M.Z.; Matthews, P.M.; et al. Tract-based spatial statistics: Voxelwise analysis of multi-subject diffusion data. Neuroimage 2006, 31, 1487-1505. [CrossRef] [PubMed]

22. Ball, G.; Srinivasan, L.; Aljabar, P.; Counsell, S.J.; Durighel, G.; Hajnal, J.V.; Rutherford, M.A.; Edwards, A.D. Development of cortical microstructure in the preterm human brain. Proc. Natl. Acad. Sci. USA 2013, 110, 9541-9546. [CrossRef]

23. Jenkinson, M.; Bannister, P.; Brady, M.; Smith, S. Improved optimization for the robust and accurate linear registration and motion correction of brain images. Neuroimage 2002, 17, 825-841. [CrossRef] [PubMed]

24. Jenkinson, M.; Beckmann, C.F.; Behrens, T.E.; Woolrich, M.W.; Smith, S.M. Fsl. Neuroimage 2012, 62, 782-790. [CrossRef] [PubMed]

25. Zhang, Y.; Brady, M.; Smith, S. Segmentation of brain MR images through a hidden Markov random field model and the expectation-maximization algorithm. IEEE Trans. Med. Imaging 2001, 20, 45-57. [CrossRef]

26. Braak, H.; Del Tredici, K. Invited Article: Nervous system pathology in sporadic Parkinson disease. Neurology 2008, 70, 1916-1925. [CrossRef]

27. Dickson, D.W.; Uchikado, H.; Fujishiro, H.; Tsuboi, Y. Evidence in favor of Braak staging of Parkinson's disease. Mov. Disord. 2010, 25, S78-S82. [CrossRef]

28. Kamagata, K.; Zalesky, A.; Hatano, T.; Ueda, R.; Di Biase, M.A.; Okuzumi, A.; Shimoji, K.; Hori, M.; Caeyenberghs, K.; Pantelis, C.; et al. Gray Matter Abnormalities in Idiopathic Parkinson's Disease: Evaluation by Diffusional Kurtosis Imaging and Neurite Orientation Dispersion and Density Imaging. Hum. Brain. Mapp. 2017, 38, 3704-3722. [CrossRef]

29. Ashburner, J.; Friston, K.J. Voxel-based morphometry-The methods. Neuroimage 2000, 11, 805-821. [CrossRef]

30. Ashburner, J. A fast diffeomorphic image registration algorithm. Neuroimage 2007, 38, 95-113. [CrossRef]

31. Cohen, J. A power primer. Psychol. Bull. 1992, 112, 155-159. [CrossRef] [PubMed]

32. Wang, Y.; Wang, Q.; Haldar, J.P.; Yeh, F.C.; Xie, M.; Sun, P.; Tu, T.W.; Trinkaus, K.; Klein, R.S.; Cross, A.H.; et al. Quantification of increased cellularity during inflammatory demyelination. Brain 2011, 134, 3590-3601. [CrossRef] [PubMed]

33. Wang, Q.; Liu, Y.; Zhou, J. Neuroinflammation in Parkinson's disease and its potential as therapeutic target. Transl. Neurodegener. 2015, 4, 19. [CrossRef] [PubMed]

34. Reid, B.E.; Di Biase, M.A.; Pomper, M.G.; Shenton, M.E.; Du, Y.; Coughlin, J.M.; Pasternak, O. Examining Links Between Free Water and a TSPO-PET Marker of Neuroinflammation. In Proceedings of the ISMRM 27th Annual Meeting and Exhibition, Montreal, QC, Canada, 11-16 May 2019.

35. Cochrane, C.J.; Ebmeier, K.P. Diffusion tensor imaging in parkinsonian syndromes: A systematic review and meta-analysis. Neurology 2013, 80, 857-864. [CrossRef] [PubMed]

36. Luk, K.C.; Lee, V.M. Modeling Lewy pathology propagation in Parkinson's disease. Parkinsonism Relat. Disord. 2014, 20, S85-S87. [CrossRef]

37. Lu, H.; Jensen, J.H.; Ramani, A.; Helpern, J.A. Three-dimensional characterization of non-gaussian water diffusion in humans using diffusion kurtosis imaging. NMR Biomed. 2006, 19, 236-247. [CrossRef]

38. Lee, J.E.; Chung, M.K.; Lazar, M.; DuBray, M.B.; Kim, J.; Bigler, E.D.; Lainhart, J.E.; Alexander, A.L. A study of diffusion tensor imaging by tissue-specific, smoothing-compensated voxel-based analysis. Neuroimage 2009, 44, 870-883. [CrossRef]

39. Rathi, Y.; Pasternak, O.; Savadjiev, P.; Michailovich, O.; Bouix, S.; Kubicki, M.; Westin, C.F.; Makris, N.; Shenton, M.E. Gray matter alterations in early aging: A diffusion magnetic resonance imaging study. Hum. Brain Mapp. 2014, 35, 3841-3856. [CrossRef]

40. Taylor, K.I.; Sambataro, F.; Boess, F.; Bertolino, A.; Dukart, J. Progressive Decline in Gray and White Matter Integrity in de novo Parkinson's Disease: An Analysis of Longitudinal Parkinson Progression Markers Initiative Diffusion Tensor Imaging Data. Front. Aging Neurosci. 2018, 10, 318. [CrossRef] 
41. Agosta, F.; Canu, E.; Stojkovic, T.; Pievani, M.; Tomic, A.; Sarro, L.; Dragasevic, N.; Copetti, M.; Comi, G.; Kostic, V.S.; et al. The topography of brain damage at different stages of Parkinson's disease. Hum. Brain Mapp. 2013, 34, 2798-2807. [CrossRef]

42. Rektor, I.; Svatkova, A.; Vojtisek, L.; Zikmundova, I.; Vanicek, J.; Kiraly, A.; Szabo, N. White matter alterations in Parkinson's disease with normal cognition precede grey matter atrophy. PLoS ONE 2018, 13, e0187939. [CrossRef] [PubMed]

43. Hattori, T.; Orimo, S.; Aoki, S.; Ito, K.; Abe, O.; Amano, A.; Sato, R.; Sakai, K.; Mizusawa, H. Cognitive status correlates with white matter alteration in Parkinson's disease. Hum. Brain Mapp. 2012, 33, 727-739. [CrossRef] [PubMed]

44. Mukaetova-Ladinska, E.B.; McKeith, I.G. Pathophysiology of synuclein aggregation in Lewy body disease. Mech. Ageing Dev. 2006, 127, 188-202. [CrossRef] [PubMed]

45. Rub, U.; Del Tredici, K.; Schultz, C.; Ghebremedhin, E.; de Vos, R.A.; Jansen Steur, E.; Braak, H. Parkinson's disease: The thalamic components of the limbic loop are severely impaired by alpha-synuclein immunopositive inclusion body pathology. Neurobiol. Aging 2002, 23, 245-254. [CrossRef]

46. Salsone, M.; Cerasa, A.; Arabia, G.; Morelli, M.; Gambardella, A.; Mumoli, L.; Nistico, R.; Vescio, B.; Quattrone, A. Reduced thalamic volume in Parkinson disease with REM sleep behavior disorder: Volumetric study. Parkinsonism Relat. Disord. 2014, 20, 1004-1008. [CrossRef] [PubMed]

47. Hawkes, C.H.; Del Tredici, K.; Braak, H. A timeline for Parkinson's disease. Parkinsonism Relat. Disord. 2010, 16, 79-84. [CrossRef] [PubMed]

48. Cheng, H.C.; Ulane, C.M.; Burke, R.E. Clinical progression in Parkinson disease and the neurobiology of axons. Ann. Neurol. 2010, 67, 715-725. [CrossRef] [PubMed]

49. Lenfeldt, N.; Hansson, W.; Larsson, A.; Nyberg, L.; Birgander, R.; Forsgren, L. Diffusion tensor imaging and correlations to Parkinson rating scales. J. Neurol. 2013, 260, 2823-2830. [CrossRef]

50. Zhang, Y.; Wu, I.W.; Buckley, S.; Coffey, C.S.; Foster, E.; Mendick, S.; Seibyl, J.; Schuff, N. Diffusion tensor imaging of the nigrostriatal fibers in Parkinson's disease. Mov. Disord. 2015, 30, 1229-1236. [CrossRef]

51. Wen, M.C.; Heng, H.S.; Ng, S.Y.; Tan, L.C.; Chan, L.L.; Tan, E.K. White matter microstructural characteristics in newly diagnosed Parkinson's disease: An unbiased whole-brain study. Sci. Rep. 2016, 6, 35601. [CrossRef]

52. Andica, C.; Kamagata, K.; Hatano, T.; Okuzumi, A.; Saito, A.; Nakazawa, M.; Ueda, R.; Motoi, Y.; Kamiya, K.; Suzuki, M.; et al. Neurite orientation dispersion and density imaging of the nigrostriatal pathway in Parkinson's disease: Retrograde degeneration observed by tract-profile analysis. Parkinsonism Relat. Disord. 2018, 51, 55-60. [CrossRef] [PubMed]

53. Perlmutter, J.S. Assessment of Parkinson disease manifestations. Curr. Protoc. Neurosci. 2009, 49, 10.1.1-10.1.14. [CrossRef] [PubMed]

54. Barbagallo, G.; Caligiuri, M.E.; Arabia, G.; Cherubini, A.; Lupo, A.; Nistico, R.; Salsone, M.; Novellino, F.; Morelli, M.; Cascini, G.L.; et al. Structural connectivity differences in motor network between tremor-dominant and nontremor Parkinson's disease. Hum. Brain Mapp. 2017, 38, 4716-4729. [CrossRef] [PubMed]

55. Iranzo, A.; Santamaria, J.; Rye, D.B.; Valldeoriola, F.; Marti, M.J.; Munoz, E.; Vilaseca, I.; Tolosa, E. Characteristics of idiopathic REM sleep behavior disorder and that associated with MSA and PD. Neurology 2005, 65, 247-252. [CrossRef] [PubMed]

56. Suzuki, M.; Hashimoto, M.; Yoshioka, M.; Murakami, M.; Kawasaki, K.; Urashima, M. The odor stick identification test for Japanese differentiates Parkinson's disease from multiple system atrophy and progressive supra nuclear palsy. BMC Neurol. 2011, 11, 157. [CrossRef] [PubMed]

(C) 2019 by the authors. Licensee MDPI, Basel, Switzerland. This article is an open access article distributed under the terms and conditions of the Creative Commons Attribution (CC BY) license (http://creativecommons.org/licenses/by/4.0/). 